\title{
Effect of occupational stress and remote working on psychological well-being of employees: an empirical analysis during covid-19 pandemic concerning information technology industry in hyderabad
}

\author{
Dr. KDV Prasada, Dr. Rajesh W. Vaidyab ${ }^{b}$, Dr. Mruthyanjaya Rao Mangipudic
}

${ }^{a}$ International Crops Research Institute for Semi-Arid Tropics (ICRISAT), Telangana, Hyderabad, India, ${ }^{b}$ Assistant Professor, Faculty In-charge Training and Placement, (DMT), *Shri Ramdeobaba College of Engineering and Management*, Ramdeo Tekdi, Gittikhadan, Katol Road, Nagpur, India, 'Karvy Stock Broking Limited, Financial District, Gachibowli, Hyderabad, India

\section{Abstract}

Purpose: In the aftermath of national lockdown due to Covid-19, several organizations were forced to opt remote working, which provides several challenges and opportunities to the employees and employer. The reason for carrying out this empirical study is that the subject is new, challenging, and occupational stress exists everywhere; also, an inadequate research has been reported on such type of studies. This empirical study reports the results of the effect of occupational stress and remote working on employees' psychological well-being in the Information Technology industry. Methodology: The effect of seven independent occupational stress-causing factors including workload, peer, physiological factors, role ambiguity, organization climate, psychological factors and job satisfaction, and an independent factor, remote working, on the dependent factor of psychological well-being of employees in Information Technology industry was measured. The psychological well-being was measured with six subscales - environment mastery, positive growth, positive relations, self-acceptance, autonomy, and purpose of life. The independent factors were measured using a survey instrument, a structured undisguised questionnaire, whereas dependent factors were measured with a shortened version of 18-item Ryff's scale. The inferences of the outcome were made using appropriate statistical procedures. Findings: The multiple regression analysis results revealed independent factors like peer, role ambiguity, organization climate, and job satisfaction are significantly influencing the psychological well-being of the employees in the Information Technology Industry. There are minor statistically significant gender and age group differences that are affecting the psychological well-being of employees as observed. Implications: The study implies that wherever possible, the remote working options need to be worked out by the employer, in all the sectors to reduce the stress and enhance the psychological well-being of employees. Originality: Till now, no researcher has reported such type of empirical study, and the available literature is limited to occupational stress in general, without suggesting how remote working affects the psychological well-being of employees in particular.

Keywords: Occupational stress, multiple regression, cronbach alpha, psychological well-being, remote working

\section{*Corresponding author:}

Dr. KDV Prasad, International Crops Research Institute for Semi-Arid Tropics (ICRISAT), Telangana, Hyderabad, India. E-mail: prasadkanaka2003@yahoo.co.in

Received: 27 March 2020; Accepted: 01 May 2020

DOI: $10.18843 / \mathrm{ijcms} / \mathrm{v} 11 \mathrm{i} 2 / 01$ 


\section{INTRODUCTION}

\section{Occupational Stress}

The occupational stress has noticeable functional, emotional and behavioural effect on performance of employees across the globe, irrespective of the organization and type of employment. Though with the advancement of science and technology and economic growth, the majority of the working community is experiencing moderate to high-level occupational stress in general and associated causes of occupational stress such as behavioural changes, physiological disorders, psychological changes on an employee, and decreased performance in particular. The contribution of the researchers for the last two decades on stress was recognised as important because of the continuous social changes, changes in lifestyle and cultural environment of the working societies, and are disturbing work-life balance, employee performance, and in turn, affect organization's productivity. Stress is man's change in nature or reaction to the circumstances that are outside and cause behavioural, psychological, and physical changes. The job stress is a result of uncontrolled physical and demands on a human being (Ivancevich \& Matteson, 1993). The concept of stress is fraught with no simple meanings of culture, and suffers from too much knowledge and too little understanding(Selye, 1980). The term stress is drawn from the Latin word "Stringere" to mean adversity, discomfort, pain, and unpleasant situation or affliction. The stress can be realized from the environmental stressors, society, physiological factors, and man's thinking (Matthews, 2001). Stress is continuous and evolving; an unexpected situation where a person is baffled with an opportunity, high peremptory requests, or resources related to what an individual wanted, and that result is judged as unclear and important (Schuler, 1980). Occupational stress is a condition where the employee is moving away from normal situations (Beehr \& Newman, 1978). The unlikable emotional and $\mathrm{t}$ physical reaction has resulted in the mismatch among requirements of the work with the skill and resource requirements of a worker (Sumanjeet, 2005).

\section{Remote Working}

In the recent past, Remote Work has become a buzz phrase in particular Information Technology (IT), and IT-enabled sectors mainly to retain talent and attrition. The remote working has now become mainstream in many services and research sectors and organizations are identifying and defining the ways to find out the activities that can be completed remotely, using the latest know-how communication technologies. Remote work is a working pattern that encourages professionals to work beyond the conventional office setting. In another way, commuting to the workplace every day and work from a fixed desk, the remote workforce can carry out their activities and tasks, and achieve their goals anywhere they opt. The beauty of remote work is that an employee can choose to work in a way that makes work-life balance perfect. However, some employees need to visit the office monthly/fortnight to have face to face peer meetings with an opportunity to work remotely for the majority of the working week, but have to commute to in-person meetings at the office one day a week. The coworking spaces fall between full traditional workplace and remote work or work from home (Remote year, 2020; Royal Society for Public Health in the UK, 2014, PGi 2014).

As part of benefits to the employer, higher productivity as the employee puts more effort, increased cost savings as the decrease in office rent, infrastructure and maintenance costs, and higher employee engagement.

\section{REVIEW OF LITERATURE}

\section{Occupational Stress}

The occupational stress or employment stress, a silent killer, is now a widely recognized problem by the social scientists, health specialists, and all organizations, including industry, research, information technology, and IT-enabled services. Occupational stress poses significant effect on the health of an employee at the individual level which leads to absenteeism, less motivation, low instinct to perform, low productivity, fatigue, no inquisitiveness to learn new things and develop new ideas and effect on employee's performance and no or less interest in work (Cooper and Marshal, 1976; Matteson and Invancevich, 1987). Most of the researchers concluded that stress was found to be affected by a variety of personal and situational factors and the perception of an individual of those factors. Chun-Tung Li, et al., (2016) presented a unique approach towards the recognition of stress using survey data from wearable sensors, smartphones, and computers, to establish if behaviour components can help differentiate good stress from another kind of stress. This in situ surveys where data was collected based on smartphone and computer usage, heartbeat rate. The correlation studies and multivariate analysis were carried out to construct the behavioural features. This method reported encouraging results in identifying or measuring the eustress. Simin Bemana, et al., (2013) reported the significant negative relationship between job stress and job satisfaction in 
Prasad, et al.

the study conducted using the data from municipality personnel in Iran. The results concluded that job satisfaction is a source of job stress. The demographic variables such as age, qualification, experience, position, income, and marital status will influence the experience of occupational stress. Subhash Soni, et al., (2015), studying the effect of demographic variables on organizational role stress and burnout, reported low stress for demographic variables age, high qualification, and more experience. Ramanathan and Vanitha (2011) studied the role of Indian tourism and its effect on relieving the stress and associated ailments. Abirami (2012), in his study on the Levels of stress among college teachers in Coimbatore District, reported that younger teachers below the age of 25 years and female teachers experience more stress. The researcher further suggested development of appropriate coping mechanisms to mitigate the stress.

Prasad KDV and Rajesh Vaidya (2018), in their study on causes for stress among PhD research scholars of RTM Nagpur University, reported a medium levels stress among the research scholars. Prasad, et al., (2016), in a study carried out a comparative analysis between the information technology sector, and the agricultural research sector reporting medium-level stress in both the organization with women employees experiencing high stress due to role overload and role ambiguity.

\section{Remote Working}

A remote employee is someone who is hired by a company but operates beyond the conventional office environmentworking from a nearby co-working room, from home or in any city around the globe. Employees can create a remote work case to get peer acceptance (Remote work, 2020). The world has turned into remote working or work from home concept wherever possible due to Coronavirus disease 2019 (COVID-19) an infectious disease caused by severe acute respiratory syndrome coronavirus 2 (SARS$\mathrm{CoV}-2$ ) a mutated virus which is less virulent in India. The availability of tools like team viewer, splash top, Microsoft remote desktop, zoom, Microsoft teams, and owl, some of the communication tools essential for remote working in addition to work prioritization reports, and solutions that were provided by Melanie (2020). The SCIKEY MindMatch (2020) study reported that $99.8 \%$ of workforce in the IT sector are incapable of remote working as reported in Economic Times.

Daniel Wheatley (2017) reported the positive impact of flexible working arrangements (FWAs), and positive effects for men and women on job satisfaction using the British Household Panel Survey and Understanding Society, 200110/11. Standy Staples (2001) reported that interpersonal trust between employee and peer is strongly associated with higher self-perceptions of performance, job satisfaction, and lower occupational stress and weak support of physical connectivity and its impact. Kristen Senz (2019) reported that remote working for the companies could add $\$ 1.3$ billion in each year based on a patent's average value, and this productivity gain could add $\$ 1.3$ billion of value to the US economy in year based on the patent average. Hickman (2019) reported from Gallup Research data that remote work improves business outcomes, attracts talent, and an engaged workforce has the best financial outcomes. Hickman (2019) stated that how workplace isolation will influence a remote worker because of a lack of management acumen and organizational expertise to develop implement strategies on remote work policies and procedures.

\section{Research Question}

Are there any challenges and benefits regarding the psychological well-being of the employees who work remotely during the Covid-19 lockdown?

\section{Research Gap}

The Union Government announced a three-week lockdown from March 24 to April 14 and extended till May 03, 2020. The idea behind the lockdown is to contain the spread of the virus, maintaining social distance among human beings. To maintain social distance, several organizations decided wherever possible, that their employees will perform their daily routine assignments remotely. The remote working options was followed in almost all sectors of employees. As the Covid-19 Pandemic was reported during December 2019 , there are no specific research articles, reviews of reports available in particular, related to occupational stress and remote working, and their effect on the psychological well-being of an employee during Covid-19 or any similar situation in the past. Further, there is not a single article reported on the psychological well-being of the remote working employees during any pandemic time in the past. Therefore, the authors considered carrying out this study surveying the remote working employees from March 24 to April 24, 2020, and reported the results.

\section{OBJECTIVES OF THE STUDY}

- To study the effect of occupational stress and remote 
working on employees' psychological well-being in the Information Technology industry

- To study if there are gender and age differences that influence the psychological well-being of the employees in the Information Technology industry

\section{RESEARCH METHODOLOGY}

Theoretical Framework: The author followed theoretical framework proposed by Prasad, et al., (2016), (2018), (2020) on occupational stress and coping strategies (Figure 1).

\section{Hypotheses}

After reviewing the literature and identifying the problem, the following hypotheses were framed:

$\mathbf{H}_{\mathrm{a} 1}$ : Effect of occupational stress and remote working is statistically significant on the psychological well-being of an employee during the Covid-19 Pandemic.

$\mathbf{H}_{\mathrm{a} 2}$ : There are significant gender and age differences among the respondents on occupational stress and remote working factors affecting the psychological well-being of the employees in IT sector.

Estimation of sample size: As the population size is unknown, the researchers used (Cochran, 1977) formula to estimate the sample size for this empirical study.

$$
\pi \Delta=\frac{z^{2} p g}{\varepsilon^{2}}
$$

Where $\mathrm{n}_{\mathrm{o}}$ is the sample size, $z$ is the selected critical value of desired confidence level, $p$ is the estimated proportion of an attribute that is present in the population, $q 1 p$ and $e$ is the desired level of precision, and this formula was used in an IT sector where the population is unknown assuming the maximum variability which is equal to $50 \%(\mathrm{P}=0.5)$ and taking $95 \%$ confidence level with $\pm 5 \%$ precision, the required sample size is:

$\mathrm{P}=0.5$ and hence $\mathrm{q}=1-0.5=0.5 ; \mathrm{e}=0.05$ and $\mathrm{z}=1.96$

$$
\pi_{0}=\frac{(1.95)^{2}(0.5)(0.5)}{(0.05)^{2}}=384.16=384
$$

Therefore, we have chosen a sample size of $>384$ i.e., 400 selected from the population of information technology industry in Hyderabad Metro.

The sample demography and description are presented in Tables 1 and 2 and the study variables, both dependent and independent, are presented in Table 3.

\begin{tabular}{lcc}
\multicolumn{2}{c}{ Table 1: Demographic characteristics of the } \\
subjects \\
Gender & Frequency & Percent \\
\hline Men & 238 & 59.5 \\
Women & 162 & 40.5 \\
Total & 400 & 100 \\
\hline
\end{tabular}

Source: Primary data

Table 2: Sample sescription

\begin{tabular}{lc} 
& Table 2: Sample sescription \\
Age group & Number of respondents \\
\hline $20-30$ & 150 \\
$31-40$ & 110 \\
$41-50$ & 75 \\
$51-60$ & 65 \\
\hline
\end{tabular}

Source: Primary data

Table 3: Independent factors that measured dependent factor affecting the psychological well-being

\begin{tabular}{llc} 
Factor & Description & No. of items \\
\hline 1 & Workload & 4 \\
2 & Peer & 5 \\
3 & Physiological factors & 3 \\
4 & Role ambiguity & 5 \\
5 & Organization climate & 6 \\
6 & Job satisfaction & 5 \\
7 & Psychological factors & 4 \\
8 & Remote working & 5
\end{tabular}

Dependent factors - psychological well-being

\begin{tabular}{llc}
\hline Factor & Description & No. of items \\
\hline 1 & Environment mastery & 3 \\
2 & Positive growth & 3 \\
3 & Positive relations & 3 \\
4 & Self-acceptance & 3 \\
5 & Autonomy & 3 \\
6 & Purpose of life & 3 \\
\hline
\end{tabular}

Based on shortened version psychological well-being scale Ryff and Keyes (1995) 
Tables 1 and 2 and the study variables, both dependent and independent, are presented in Table 3.

\section{Research Instrument}

\section{Measurement of occupational stress and remote working factors}

A standardized, undisguised research instrument based on five points Likert scale, with a rating scale of Strongly agree $=5$; Agree $=4$; Neutral =3; Disagree $=2$; Strongly disagree 2 were used to measure the eight independent occupational stress-causing factors as per the model of Prasad, et al. (2016), (2018). The total measured items are 37.

\section{Measurement of psychological well-being factors}

A shortened version of an 18-point scaler developed by Ryff and Keyes (1995) was used. This is a 7-point rating scale with Strongly agree $=7$, Somewhat agree $=6$, A little agree $=5$, Neither agree nor disagree $=4$, A little disagree $=3$, Somewhat disagree $=2$, Strongly disagree $=1$ and the factors measured are Autonomy, Environmental Mastery, Personal Growth, Positive Relations, Purpose in Life and the Self-Acceptance with 3 items for each factor.

There are some items worded in the opposite way on the measurement scale. Reverse-scored was measured using the following method

$(($ Number of points on the scale $)+1)-($ Answer from the respondent)

For example, if Question 1 is a 7-point scale and the respondent answered three on Question 1, the recoded answer was: $(7+$ 1) $-3=5$, therefore five was entered for this response.

The researchers have used two types of Likert scales, one with 5-point and another with a 7-point scale. For easy analysis, the researchers have transformed the two Likert scales used into one 5-point common scale of Likert type. The linear transformation procedure was used to convert the 7-point scale to a 5-point scale, using the following formulas.

$$
X=(x-a) /(b-a)
$$

Just substitute a for $\mathrm{x}$ to make the result as 0 , and then substitute $\mathrm{b}$ for $\mathrm{x}$ to see that the result is 1 . This will be continued in stage two using new minimum to be $\mathrm{A}$ and the new maximum to be $\mathrm{B}$. The transformation will be:

$$
\mathrm{Y}=(\mathrm{B}-\mathrm{A}) * \mathrm{X}+\mathrm{A}
$$

Substitute 0 for $\mathrm{X}$ to see that the result is $\mathrm{A}$, and 1 for $\mathrm{X}$ to see that the result is $\mathrm{B}$.

Combining all whole first transformation in place of $\mathrm{X}$ in the second:

$$
\mathrm{Y}=(\mathrm{B}-\mathrm{A}) *(\mathrm{x}-\mathrm{a}) /(\mathrm{b}-\mathrm{a})+\mathrm{A} .
$$

\section{DATA ANALYSIS}

The researchers have applied statistical techniques that suit the study to draw the inferences and conclusions from primary data. The researchers used descriptive statistics, standard deviation, and dispersion methods. Psychological well-being was categorized as low, medium, and high level. All the data analysis was carried out using statistical package for social sciences (SPSS) version 26 (SPSS Inc., Chicago, Ill., USA). The researchers have carried out the correlation studies and observed most of the correlations are positive and significant (Table 4).

\section{Reliability of Methods}

For internal consistency, the reliability of the questionnaire was assessed using Cronbach's alpha value (Cronbach, 1951) Split-Half (odd-even) Correlation, Split-Half with Spearman-Brown Adjustment. The values in Table 5 indicate that the survey instrument is reliable and consistent.

\section{RESULTS}

\section{Results of Multiple Regression Analysis}

The multiple regression analysis was carried out to examine whether " $\mathrm{T}$ there was a correlation between stress levels, remote working, and psychological well-being of employees of IT sector using over the sample $(n=400)$. All the assumptions needed for running multiple regression was carried out. There was independence of residuals, as assessed by Durbin-Watson statistic of 1.844 . The bivariate product-moment correlation between occupational stress, remote working, and psychological well-being presented in Table 5 .

The multiple correlation coefficient, $R$ is the Pearson correlation coefficient between the scores predicted by the regression model (i.e., the predicted scores) and the actual values of the 


\section{Table 4: Correlation coefficients of the study variables}

\begin{tabular}{|c|c|c|c|c|c|c|c|c|c|c|c|c|c|c|c|}
\hline & 1 & 2 & 3 & 4 & 5 & 4 & 7 & 8 & 9 & 10 & 11 & 12 & 13 & 14 & 15 \\
\hline 1 & 1 & & & & & & & & & & & & & & \\
\hline 2 & $.34^{\star \star}$ & 1 & & & & & & & & & & & & & \\
\hline 3 & $.57^{\star \star}$ & $.38^{\star *}$ & 1 & & & & & & & & & & & & \\
\hline 4 & $.42^{\star *}$ & $.66^{\star *}$ & $.50^{\star *}$ & 1 & & & & & & & & & & & \\
\hline 5 & $.18^{\star \star}$ & $.60^{\star *}$ & $.26^{* *}$ & $.47^{\star *}$ & 1 & & & & & & & & & & \\
\hline 6 & 0.08 & $.70^{\star *}$ & $.18^{\star \star}$ & $.48^{* *}$ & $.69^{* *}$ & 1 & & & & & & & & & \\
\hline 7 & $-.10^{*}$ & $.51^{* *}$ & 0.02 & $.31^{* *}$ & $.40^{* *}$ & $.65^{\star *}$ & 1 & & & & & & & & \\
\hline 8 & -0.01 & $.47^{\star \star}$ & 0.03 & $.32^{* *}$ & $.40^{\star *}$ & $.67^{\star *}$ & $.76^{* \star}$ & 1 & & & & & & & \\
\hline 9 & 0.06 & $.24^{\star *}$ & $.14^{\star *}$ & $.15^{\star *}$ & $.10^{*}$ & $.38^{* *}$ & $.35^{\star *}$ & $.43^{\star *}$ & 1 & & & & & & \\
\hline 10 & $.17^{\star \star}$ & $.44^{\star *}$ & $.22^{\star \star}$ & $.30^{\star *}$ & $.21^{* *}$ & $.46^{\star *}$ & $.31^{* *}$ & $.38^{\star *}$ & $.64^{\star *}$ & 1 & & & & & \\
\hline 11 & $.13^{\star *}$ & $.29^{\star *}$ & $.23^{\star *}$ & $.25^{\star *}$ & $.15^{\star *}$ & $.37^{\star *}$ & $.26^{* *}$ & $.44^{\star *}$ & $.77^{* *}$ & $.71^{\star *}$ & 1 & & & & \\
\hline 12 & 0.09 & $.22^{\star \star}$ & $.17^{\star *}$ & $.18^{\star \star}$ & $.17^{\star *}$ & $.36^{* *}$ & $.29^{* *}$ & $.44^{\star *}$ & $.74^{\star *}$ & $.68^{\star \star}$ & $.88^{\star \star}$ & 1 & & & \\
\hline 13 & $.14^{\star *}$ & $.29^{\star \star}$ & $20^{* *}$ & $.22^{* *}$ & $.16^{* *}$ & $.38^{* *}$ & $.29^{* *}$ & $.42^{* *}$ & $.67^{* *}$ & $.71^{* *}$ & $.79^{\star *}$ & $.74^{\star *}$ & 1 & & \\
\hline 14 & $.14^{\star \star}$ & $.34^{\star *}$ & $.26^{\star \star}$ & $.22^{\star *}$ & $.15^{\star *}$ & $.37^{\star \star}$ & $.26^{* *}$ & $.32^{\star \star}$ & $.68^{* *}$ & $.81^{* *}$ & $.80^{\star *}$ & $.74^{* *}$ & $.77^{\star \star}$ & 1 & \\
\hline 15 & $.14^{\star \star}$ & $.34^{* *}$ & $.23^{\star *}$ & $.25^{\star *}$ & $.18^{* *}$ & $.43^{\star *}$ & $.33^{* *}$ & $.46^{\star *}$ & $.84^{* *}$ & $.85^{\star *}$ & $.93^{\star *}$ & $.90^{\star *}$ & $.88^{* *}$ & $.90^{* *}$ & 1 \\
\hline
\end{tabular}

1. Workload; 2. Remote work; 3. Peer; 4. Physiological factors; 5. Role ambiguity; 6. Organization climate; 7. Psychological factors; 8. Job satisfaction 9. Environment mastery; 10. Personal growth; 11. Autonomy, 12. Self-acceptance; 13. Purpose of life, 14. Positive relations; 1 '5. Psychological well-being overall *. Correlation is significant at the 0.05 level (2-tailed). ${ }^{* \star}$. Correlation is significant at the 0.01 level (2-tailed).

Table 5: Independent and dependent factors of the study

\begin{tabular}{llccc} 
Factor & Description & C-alpha & $\begin{array}{c}\text { Split-half (odd-even) } \\
\text { correlation }\end{array}$ & $\begin{array}{c}\text { Split-half with Spearman-Brown } \\
\text { Adjustment }\end{array}$ \\
\hline 1 & Workload & 0.68 & 0.47 & 0.60 \\
2 & Peer & 0.71 & 0.62 & 0.76 \\
3 & Physiological factors & 0.76 & 0.62 & 0.75 \\
4 & Role ambiguity & 0.67 & 0.60 & 0.74 \\
5 & Organization climate & 0.80 & 0.66 & 0.82 \\
6 & Job satisfaction & 0.74 & 0.50 & 0.66 \\
7 & Psychological factors & 0.83 & 0.74 & 0.85 \\
8 & Remote working & 0.83 & 0.60 & 0.76 \\
\hline & & & & \\
\hline Factor & Description & Psychological well-being (Dependent factors) & 0.72 \\
\hline 1 & Environment mastery & 0.79 & 0.60 & 0.72 \\
2 & Positive growth & 0.74 & 0.55 & 0.80 \\
3 & Positive relations & 0.88 & 0.68 & 0.84 \\
4 & Self-acceptance & 0.82 & 0.74 & 0.79 \\
5 & Autonomy & 0.84 & 0.65 & 0.77 \\
6 & Purpose of life & 0.84 & 0.66 & 0.96 \\
& Overall-Psychological well-being & 0.97 & 0.91 & 0.96 \\
& Overall-Independent factors & 0.93 & 0.87 &
\end{tabular}

Overall C-alpha:0.93 
dependent variable. The value of $R 0.447$ (Table 6), in this example, indicates a moderate level of association. The $R^{2}$ is equal to 0.199 in Table 6 which indicates that the addition of all our independent variables into a regression model explained $19.9 \%$ of the variability of our dependent variable, psychological well-being (compared to the mean model).

Statistical significance of the model: The significance value in ANOVA (Table 7) is 0.000 which actually means that $\mathrm{P}<0.0005$, and $\mathrm{P}<0.05$ is a statistically significant result, and addition of all independent variables leads to a model that is statistically significant and outcome variable will be predicted. The results are $\mathrm{F}(2,397)=49.435, \mathrm{P}<0.0005$; where $\mathrm{F}$ indicated that a comparison with $\mathrm{F}$-distribution (F-test) is made, 2 in $(2,397)$ is degrees of freedom, 397 in $(2,397)$ indicate the residual degree of freedom, 49.435 is obtained value of the F-statistic i.e., F-value and $\mathrm{P}<0.0005$ is the probability of obtaining the observed F-value if the null hypothesis is true (Table 6).

Interpreting the coefficients: The regression equation for the model can be expressed as:

Psychological well-being $=$ bo $(\mathrm{b} 1 \mathrm{x}$ occupational stress $)+(\mathrm{b} 2$ $\mathrm{x}$ Remote working)

Psychological well-being: $1.360+(-0.247)$ (remote work $(+0.757$ (occupational stress overall).

Occupational stress was significantly influencing the dependent variable of psychological well-being. The coefficient value of stress 0.757 represented the change in the dependent variable of psychological well-being for one-unit change in the independent variable, occupational stress overall. For one unit of increase of occupational stress, 0.757 units of psychological well-being will

$\begin{aligned} & \text { Table 6: Model summary of occupational stress overall remote working and psychological well-being } \\
& - \text { overall }(\boldsymbol{n}=\mathbf{4 0 0})\end{aligned}$
\begin{tabular}{lccccc} 
Model & $\mathbf{R}$ & $\mathbf{R}$ Square & Adjusted R Square & Std. Error of the Estimate & Durbin-Watson \\
\hline 1 & $.447^{\mathrm{a}}$ & 0.199 & 0.195 & 0.74651 & 1.844 \\
\hline
\end{tabular}

a. Predictors: (Constant), stress overall, remote work, b. Dependent Variable: Psychological well-being overall

Table 7: ANOVA summary of the occupational stress, remote working and psychological

\begin{tabular}{llccccc} 
Well-being $^{\text {a }}$ & & Sum of squares & df & Mean square & F & Sig. \\
\hline 1 & Regression & 55.097 & 2 & 27.549 & 49.435 & $.000^{\mathrm{b}}$ \\
& Residual & 221.236 & 397 & 0.557 & & \\
& Total & 276.334 & 399 & & & \\
\hline
\end{tabular}

a. Dependent Variable: Psychological Well-being overall, b. Predictors: (Constant), stress overall, remote work

\begin{tabular}{|c|c|c|c|c|c|c|}
\hline \multirow[t]{2}{*}{ Model } & & Unstandardized coefficients & \multirow[t]{2}{*}{ Std. Error } & Standardized coefficients & \multirow[t]{2}{*}{$\mathbf{t}$} & \multirow[t]{2}{*}{ Sig. } \\
\hline & & B & & Beta & & \\
\hline \multirow[t]{3}{*}{1} & (Constant) & 1.360 & 0.226 & & 6.021 & 0.000 \\
\hline & Remote work & -0.104 & 0.085 & -0.104 & -1.227 & 0.221 \\
\hline & Stress overall & 0.757 & 0.121 & 0.531 & 6.275 & 0.000 \\
\hline
\end{tabular}

a. Dependent Variable: Psychological well-being overall

Table 9: Model summaryb of occupational stress, remote working, and psychological well-being

\begin{tabular}{lccccc} 
Model & $\mathbf{R}$ & $\mathbf{R}$ square & Adjusted R square & Std. Error of the estimate & Durbin-Watson \\
\hline 1 & $.565^{\mathrm{a}}$ & 0.319 & 0.305 & 0.69381 & 1.888 \\
\hline $\begin{array}{l}\text { a. Predictors: (Constant), job satisfaction, workload, role ambiguity, peer, physiological factors, remote work, psychological factors, } \\
\text { organization climate, b. Dependent Variable: Psychological well-being }\end{array}$
\end{tabular}


be affected. If we consider standardized coefficients a beta value of 0.531 , it indicates that a change of one standard deviation in the independent variable, occupational stress, results in 0.382 change of standard deviations in psychological wellbeing. At this point, remote working is not a good predictor of psychological well-being (Table 8).

Therefore, the researchers further carried out the analysis with all individual independent variables to see the causal effect on the dependent variable. The $R^{2}$ is equal to 0.305 . Table 9 indicates that the addition of all independent variables into a regression model explained $30.5 \%$ of the variability of the dependent variable of psychological well-being.

Statistical significance of the model: The significance value in ANOVA (Table 10) is 0.000 which actually means that $\mathrm{P}<0.0005$, and $\mathrm{P}<0.05$ is a statistically significant result and addition of all independent variables leads to a model that is statistically significant and predicts the dependent variable better than the mean model, and statistically significantly better fit the data than the mean model. The results are F (2, $397)=22.882, \mathrm{P}<0.0005$; where $\mathrm{F}$ indicated that a comparison with F-distribution (F-test) is made, 2 in $(2,397)$ is degrees of freedom, 397 in $(2,397)$ indicate the residual degree of freedom, 22.882 is obtained as value of the F-statistic i.e., F-value and $\mathrm{P}<0.0005$ are the probability of obtaining the observed F-value if the null hypothesis is true (Table 10).

Interpretation: Using the multiple regression analysis (Table 11), it was found that the independent occupational stress factors, peer, role ambiguity, organizational climate, and job satisfaction are statistically significant, influencing the outcome of the variable, psychological well-being. The coefficient value of factor peer, 0.017 , represents the change in the dependent variable of psychological well-being for oneunit change in the independent variable overall. For one unit of increase of stress due to peer, 0.177 units of psychological wellbeing will be affected. If we consider standardized coefficients a beta value of 0.202 , it indicates that a change of one standard deviation in the independent variable of occupational stress results in 0.202 standard deviations affecting psychological well-being. In a similar way, while one unit increases stress due to organizational climate, 0.393 units of psychological wellbeing will be affected; considering the standardized beta value of 0.382 units, due to a change of one standard deviation in independent variable causing stress, 0.382 standard deviation

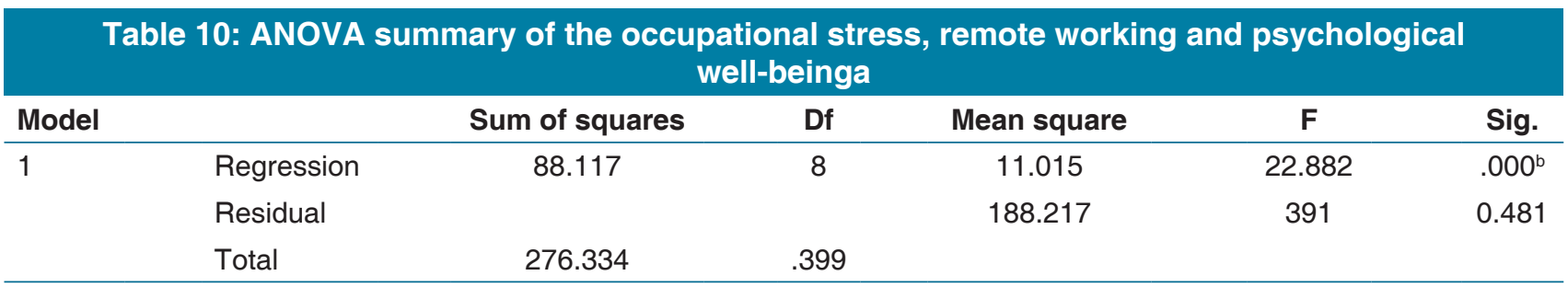

a. Dependent Variable: Psychological well-being overall, b. Predictors: (Constant), job satisfaction, workload, role ambiguity, peer, physiological factors, remote work, psychological factors, organization climate

\begin{tabular}{|c|c|c|c|c|c|c|}
\hline \multirow[t]{2}{*}{ Model } & \multirow[t]{2}{*}{ Factors } & \multirow{2}{*}{$\begin{array}{c}\text { Unstandardized coefficients } \\
\text { B }\end{array}$} & \multirow{2}{*}{$\begin{array}{l}\text { Std. } \\
\text { error }\end{array}$} & \multirow{2}{*}{$\begin{array}{c}\text { Standardized coefficients } \\
\text { Beta }\end{array}$} & \multirow[t]{2}{*}{$\mathbf{t}$} & \multirow[t]{2}{*}{ Sig. } \\
\hline & & & & & & \\
\hline \multirow[t]{9}{*}{1} & (Constant) & 1.598 & 0.226 & & 7.076 & 0.000 \\
\hline & Remote Work & 0.060 & 0.072 & 0.060 & 0.828 & 0.408 \\
\hline & Workload & 0.039 & 0.056 & 0.038 & 0.699 & 0.485 \\
\hline & Peer & 0.177 & 0.048 & 0.202 & 3.675 & 0.000 \\
\hline & Physiological Factors & -0.057 & 0.068 & -0.052 & -0.845 & 0.399 \\
\hline & Role Ambiguity & -0.268 & 0.061 & -0.266 & -4.385 & 0.000 \\
\hline & Organization Climate & 0.393 & 0.083 & 0.382 & 4.726 & 0.000 \\
\hline & Psychological & -0.097 & 0.062 & -0.111 & -1.554 & 0.121 \\
\hline & Job Satisfaction & 0.340 & 0.063 & 0.380 & 5.372 & 0.000 \\
\hline
\end{tabular}

a. Dependent Variable: Psychological well-being 
will affect psychological well-being and so on. Therefore, psychological well-being can be predicted as:

Psychological well-being $=1.598+0.060_{\text {(remote }}$ work) $+0.039_{\text {(workload) }}+0.177_{\text {(Peer) }}-0.057_{\text {(physiological factors) }}-0.268_{\text {(Role Ambiguty) }}$ $-0.393_{\text {(organization climate) }}-0.097_{\text {(Psychological factors) }}+0.340_{\text {(job satiffaction) }}$

Gender differences: A separate regression analysis was carried out to see if there are any gender differences affecting psychological well-being. From Table 12, 34.3\% and 26.4 percent variation are observed in male and female employees in the model. The ANOVA results are significant for both male and female employees (Table 13).

From the results of the multiple regression analysis, it can be observed that peer and job satisfaction are common and statistically significant both in male and female employees, whereas role ambiguity and psychological factors are statistically significant in male employees. Therefore, no significant gender differences were observed (Table 14).

The Post-hoc comparisons were carried out to see any age group differences, which were statistically significant and influenced the psychological well-being of the employees (Table 15).

Means in a row without a common superscript letter differ $(\mathrm{P}<0.05)$ as analysed by one-way ANOVA and the TUKEY test.
The Tukey HSD post-hoc analysis was carried out to find out which group is significantly different from other groups. The results are presented in Table 6. 89A, is where statistically significant groups are superscripted. As the factor peer was not significant, no post-hoc analysis was carried out for it. For the workload, there was a statistically significant difference observed among the age group 20 to $30,41-50$; whereas for job satisfaction, statistically significant differences were observed among the age group of 20-30, 31-40, and so on. This indicated that the age group differences were not statistically significant across the age groups for independent variables.

Based on the regression results and post-hoc comparisons we partially accept the null hypothesis: $\mathrm{H}_{\mathrm{o} 1}$ : Effect of occupational stress and remote working is statistically significant on the psychological well-being of an employee during Covid-19 Pandemic; and partially accept the null hypothesis on: $\mathrm{H}_{02}$ : There are significant gender and age differences on occupational stress and remote working factors affecting the psychological well-being of the employees in IT sector

\section{DISCUSSION}

Several studies were carried out on occupational stress and its effect on performance, work-life balance, and health

Table 12: Model summary of the male and female employees on occupational stress, remote working and psychological well-beingb,c

\begin{tabular}{lccccc} 
Model R & $\mathbf{R}$ & R square & Adjusted R square & Std. error of the estimate & Durbin-Watson statistic \\
\hline Male & $.604^{\mathrm{a}}$ & 0.365 & 0.343 & 0.66378 & 2.014 \\
Female & $.548^{\mathrm{a}}$ & 0.301 & 0.264 & 0.73032 & 1.743 \\
\hline
\end{tabular}

a. Predictors: (Constant), job satisfaction, peer, role ambiguity, physiological factors, workload, psychological, remote work, organization climate, c. Dependent Variable: Psychological Well-being

\begin{tabular}{llccccc}
\multicolumn{7}{c}{ Table 13: ANOVA summary of the occupational stress, remote working and } \\
Psychological well-being, \\
Model & & Sum of squares & Df & Mean square & F & Sig. \\
\hline Male & Regression & 58.095 & 8 & 7.262 & 16.482 & $.000^{\circ}$ \\
& Residual & 100.897 & 229 & 0.441 & & \\
& Total & 158.992 & 237 & & & $.000^{\circ}$ \\
Female & Regression & 35.060 & 8 & 4.382 & 8.217 & \\
& Residual & 81.604 & 153 & 0.533 & & \\
& Total & 116.664 & 161 & & & \\
\hline
\end{tabular}

a. Dependent Variable: Psychological Well-being, c. Predictors: (Constant), job satisfaction, peer, role ambiguity, physiological factors, workload, psychological, remote work, organization climate 


\begin{tabular}{|c|c|c|c|c|c|c|}
\hline Model & Factor & $\begin{array}{l}\text { Unstandardized } \\
\text { coefficients }\end{array}$ & $\begin{array}{l}\text { Coefficients } \\
\text { standard Error }\end{array}$ & $\begin{array}{l}\text { Standardized } \\
\text { coefficients beta }\end{array}$ & $\mathbf{t}$ & Sig. \\
\hline \multirow[t]{9}{*}{ Male } & (Constant) & 1.663 & 0.284 & & 5.849 & 0.000 \\
\hline & Workload & 0.107 & 0.079 & 0.108 & 1.348 & 0.179 \\
\hline & Remote work & -0.063 & 0.099 & -0.063 & -0.635 & 0.526 \\
\hline & Peer & 0.184 & 0.069 & 0.216 & 2.663 & 0.008 \\
\hline & Physiological factors & -0.115 & 0.082 & -0.106 & -1.393 & 0.165 \\
\hline & Role Ambiguity & -0.328 & 0.080 & -0.336 & -4.108 & 0.000 \\
\hline & Organization climate & 0.617 & 0.113 & 0.631 & 5.466 & 0.000 \\
\hline & Psychological & -0.151 & 0.073 & -0.185 & -2.076 & 0.039 \\
\hline & Job satisfaction & 0.296 & 0.074 & 0.355 & 3.996 & 0.000 \\
\hline \multirow[t]{9}{*}{ Female } & (Constant) & 1.330 & 0.398 & & 3.343 & 0.001 \\
\hline & Workload & -0.017 & 0.091 & -0.015 & -0.185 & 0.853 \\
\hline & Remote work & 0.114 & 0.117 & 0.111 & 0.978 & 0.330 \\
\hline & Peer & 0.169 & 0.073 & 0.183 & 2.323 & 0.022 \\
\hline & Physiological factors & 0.029 & 0.121 & 0.025 & 0.242 & 0.809 \\
\hline & Role ambiguity & -0.177 & 0.098 & -0.169 & -1.814 & 0.072 \\
\hline & Organization climate & 0.217 & 0.131 & 0.197 & 1.656 & 0.100 \\
\hline & Psychological & -0.001 & 0.117 & -0.002 & -0.013 & 0.990 \\
\hline & Job satisfaction & 0.347 & 0.119 & 0.347 & 2.921 & 0.004 \\
\hline
\end{tabular}

a. Dependent Variable: Psychological Well-being

Table 15: Post-hoc comparisons of different age groups

\begin{tabular}{lcccc} 
& $\mathbf{2 0 - 3 0 ( n = 1 5 0 )}$ & $\mathbf{3 1 - 4 0}(\mathbf{n = 1 1 0})$ & $\mathbf{4 1 - 5 0}(\mathbf{n = 7 5})$ & $\mathbf{4 5 1 - 6 0}(\mathbf{n = 6 5})$ \\
\hline A & $3.69 \pm 0.0619^{\mathrm{ab}}$ & $3.9 \pm 0.0682^{\mathrm{a}}$ & $3.48 \pm 0.105^{\mathrm{b}}$ & $3.77 \pm 0.105^{\mathrm{ab}}$ \\
B & $3.2 \pm 0.0636^{\mathrm{b}}$ & $3.55 \pm 0.0711^{\mathrm{a}}$ & $3.27 \pm 0.113^{\mathrm{ab}}$ & $3.6 \pm 0.0977^{\mathrm{a}}$ \\
C & $3.38 \pm 0.0716$ & $3.57 \pm 0.101$ & $3.33 \pm 0.109$ & $3.44 \pm 0.118$ \\
D & $3.34 \pm 0.0573^{\mathrm{b}}$ & $3.47 \pm 0.0756^{\mathrm{ab}}$ & $3.41 \pm 0.0925^{\mathrm{ab}}$ & $3.68 \pm 0.0866^{\mathrm{a}}$ \\
E & $3.12 \pm 0.0685^{\mathrm{b}}$ & $3.37 \pm 0.0806^{\mathrm{ab}}$ & $3.44 \pm 0.0909^{\mathrm{a}}$ & $3.37 \pm 0.0925^{\mathrm{ab}}$ \\
F & $3.11 \pm 0.0615^{\mathrm{b}}$ & $3.51 \pm 0.0707^{\mathrm{a}}$ & $3.43 \pm 0.0995^{\mathrm{a}}$ & $3.49 \pm 0.108^{\mathrm{a}}$ \\
G & $2.97 \pm 0.0761^{\mathrm{b}}$ & $3.23 \pm 0.0936^{\mathrm{ab}}$ & $3.22 \pm 0.113^{\mathrm{ab}}$ & $3.35 \pm 0.104^{\mathrm{a}}$ \\
H & $2.98 \pm 0.0814^{\mathrm{b}}$ & $3.35 \pm 0.0757^{\mathrm{a}}$ & $3.15 \pm 0.102^{\mathrm{ab}}$ & $3.26 \pm 0.112^{\mathrm{ab}}$ \\
I & $3.42 \pm 0.0697^{\mathrm{b}}$ & $3.74 \pm 0.0744^{\mathrm{a}}$ & $3.54 \pm 0.101^{\mathrm{ab}}$ & $3.63 \pm 0.0887^{\mathrm{ab}}$ \\
\hline
\end{tabular}

A. Workload, B; Remote work; C. Peer; D. Physiological factors, E. Role ambiguity; F. Organisational climate; G. Psychological factors, $\mathrm{H}$. Job satisfaction; and I. Psychological well-being; (Values are means \pm SEM.)

effects. However, an inadequate information is available on occupational stress, remote working effect on psychological well-being, and in particular, there is no literature available being reported during an epidemic, pandemic, or Covid-19 pandemic period. Therefore, the researchers have carried out this study surveying the IT sector employees using a questionnaire during the period March 24 to April 24, 2020. The questionnaire was published, and a link was sent to the respondents. Although, this is the first such type of study, our results are in line with the similar studies carried out by the researchers (Prasad et al., 2018; Leite A, et al., 2019; Oskrochi, et al., 2018; and Perstling, 2012) who applied the 


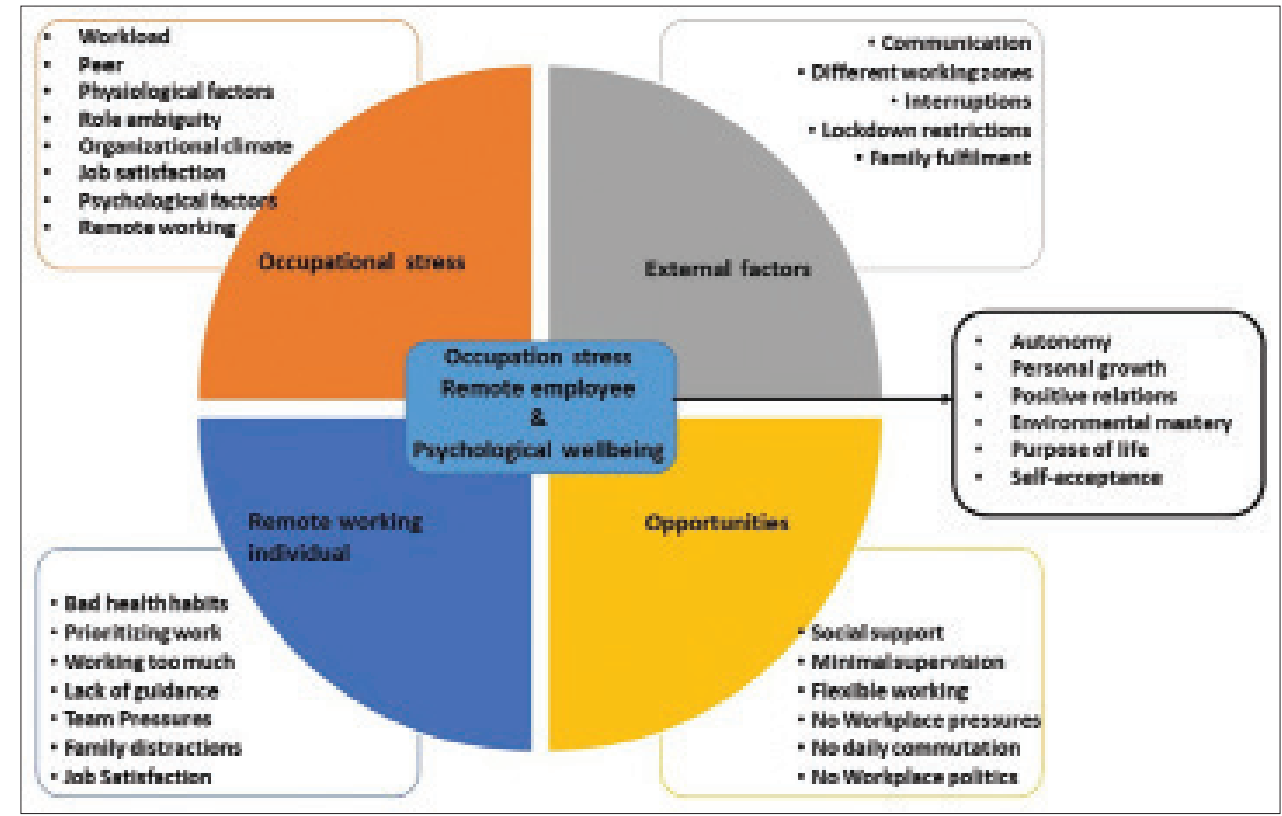

Figure 1: Theoretical framework - Occupational stress, working and psychological well-being

multiple regression analysis. The reliability of the statistics was assessed using Cronbach alpha, Split-Half (oddeven) Correlation, and Split-Half with Spearman-Brown Adjustment which indicates the survey instrument was consistent and reliable. The study used the shortened version of the psychological well-being scale, a model developed by Ryff and Keyes (1995), which is commonly used by several researchers. There were no significant gender and age group differences observed in the study; however, remote working is a challenge for employees because of workplace isolation, family disturbance, peer absence, lack of suggestions to the employees, and working too much or not working at all. However, the positive side is time savinng in commuting, flexible working hours, job control, use of new technology, saving resources like office space cost, and other opportunity costs. There are several tangibles and intangible benefits to both employee and employer.

\section{CONCLUSION}

The authors suggest that more studies need to be carried out on the subject of psychological well-being and occupational stress in other sectors also. The Covid-19 pandemic is severely affecting the health sector employees, sanitation employees. An in-depth survey will be very helpful to mitigate the causes of occupational stress, psychological well-being, and pandemic health hazards. Future research should include the employee career and development, training, and retraining aspects of remote working employees. The organization should come up with flexible policies to suit the situation in order to create a win-win situation for both the employee and employer.

\section{ACKNOWLEDGMENT}

We thank all the respondents to our survey questionnaire during the Covid-19 Pandemic Period.

\section{CONFLICT OF INTEREST}

The authors have NO affiliations with or involvement in any organization or entity with any financial or non-financial interest in the subject matter or materials discussed in this manuscript.

\section{REFERENCES}

Abirami, V. (2012). Levels of stress among college teachers with reference to Coimbatore district. Researchers World: Journal of arts, commerce and science, 3(2), 93-104.

Beehr, T., \& Newman, J. (1978). Job Stress, Employee Health and Organizational Effectiveness: A Facet Analysis, Model and Literature Review. Personnel 
Psychology, 31, 665-699. Retrieved from http://dx.doi. org/10.1111/j.1744-6570.1978.tb02118.x

Bemana, S., Moradi, H., Ghasemi, M., Taghavi, S. M., \& Ghayoor, A. H. (2013). The relationship among job stress and job satisfaction in municipality personnel in Iran. World Applied Sciences Journal, 22(2), 233-238.

Chun Tung, L. C., \& Li, T. (2016). Eustress or distress: An empirical study of perceived stress in everyday college life. In Proceedings of the 2016 ACM International Joint Conference on Pervasive and Ubiquitous Computing: Adjunct (pp. 1209-1217). ACM.

Cochran, W. G. (1977). Sampling Techniques (3rd ed.). New York: Wiley.

Cooper, C. L., \& Marshall, J. (1976). Occupational sources of stress: A review of the literature relating to coronary heart disease and mental ill health. Journal of occupational psychology, 49(1), 11-28.

Cronbach, L. (1951). Coefficient alpha and the internal structure of tests. Psychometrika, 16(3), 297-334.

Hickman, A. (2019). Workplace Isolation Occurring in Remote Workers. Minneapolis: Walden University.

Ivancevich, J., \& Matteson, M. (1993). Organisational Behaviour and Management, (3rd ed.). Homewood Irwin.

K.D.V., P., Vaidya, R., \& Anil Kumar. (2018). Association among Occupational Stress factors and performance at workplace among Agricultural Research Sector Employees at Hyderabad, India. Pacific Business Review International, 10(7), 27-36.

Kristen, S. (2019). How Companies Benefit When Employees Work Remotely. Research and Ideas. Retrieved from https://hbswk.hbs.edu/item/howcompanies-benefit-when-employees-work-remotely

Leite, A., Ramires, A., MOURA, A. D., Souto, T., \& Maroco, J. (2019). Psychological wellbeing and health perception: predictors for past, present and future. Archives of Clinical Psychiatry (São Paulo), 46(3), 53-60.

Matteson, M., \& Ivancevich, J. (1987). Controlling work stress: Effective Human Resource and Management Strategies. Jossey Bass, San Francisco.

Matthews, G. (2001). A Transactional Model of Driver Stress. In P. H. (eds), Stress, Workload and Fatigue (pp. 133-163). Mahwah, NJ: Lawrence Erlbaum.

Melanie, P. (2020). The 7 biggest remote work challenges (and how to overcome them). Retrieved from https:// zapier.com/blog/remote-work-challenges/

Oskrochi, G., Bani-Mustafa, A., \& Oskrochi, Y. (2018). Factors affecting psychological Wellbeing: Evidence from two nationally representative surveys. PloS one, 13(6).

Perstling, M., \& Rothmann, S. (2012). Secondary traumatic stress, psychological well-being and life satisfaction of social workers in Namibia. Journal of Psychology in Africa, 22(1), 1-9.

Prasad, K. D., \& Vaidya, R. (2018). Causes and effect of occupational stress and coping on performance and psychological wellbeing among the Agricultural Research Sector: An Empirical Study using Multinomial Logistic Regression Approach. Helix Journal-The Scientific Explorer, 8(6), 4114-4119.

Prasad, K., Mruthyanjaya Rao, M., Vaidya, R., \& Muralidhar, B. (2020). Remote Working: Organizational Climate, Opportunities, Challenges and Psychological Well-being of the Employees During Covid-19 Pandemic: A General Linear Model Approach with Reference to IT Industry in Hyderabad. International journal of Advanced Research in Engineering \& Technology (IJARET).

Prasad, K., Vaidya, R., \& Kumar, V. (2016). Teacher's Performance as a Function of Occupational Stress and Coping with Reference to CBSE Affiliated School Teachers in and around Hyderabad: A Multinomial Regression Approach. Psychology, 7, 1700-1718.

Ramanathan, V., \& Vanitha, A. (2011). The new age human resources in Indian tourism - role and effectiveness. Indian Journal of Commerce and Management Studies, 2(1), 210-221.

Remote working and its effects on employee health. (2014). Royal Society for Public Health in the UK, 2014, PGi 2014.

Ryff, C. D., \& Keyes, C. L. (1995). The structure of psychological wellbeing revisited. Journal of personality and social psychology, 69(4), 719.

Schuler, R. (1980). Definition and Conceptualization of Stress in Organizations. Organizational Behavior and Human Performance, 25, 184-215.

SCIKEY MindMatch. (2020). 99.8\% workforce in IT sector incapable of remote working: Study. Retrieved from https:/economictimes.indiatimes.com/tech/ites/99$8 \mathrm{pc}$-workforce-in-it-sector-incapable-of-remoteworking-study/articleshow/75080948.cms

Selye, H. (1980). Stress, aging and retirement. Journal of Mind and Behaviour, 1, 93-110.

Soni, S. R., Vyas, J., Pestonjee, D., Kher, H., Thakkar, K., \& Yanduri, V. L. (2015). Impact of the art of living programme on burnout and organizational role stress among animal husbandry personnel. Journal of Psychiatry, 18(4), 1-11.

Staples, D. S. (2001). A study of remote workers and their differences from non-remote workers. Journal of Organizational and End User Computing (JOEUC), 13(2), 3-14.

Sumanjeet. (2005). Job stress in Business Organisations: 
Prasad, et al.

Causes, Consequences, and Coping Strategies. Indian Journal of Training and Development, 35(3), 84-92.

Suryahadi, A. Y. (2011). Suryahadi, A. Y., Raya, U., Mar Accelerating poverty and vulnerability reduction: trends, opportunities and constraints. In employment, living standards and poverty in contemporary
Indonesia.

Wheatley, D. (2017). Employee satisfaction and use of flexible working arrangements. Work, employment and society, 31(4), 567-585. 